Mediscope

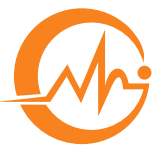

The Journal of GMC

\title{
COVID-19: Epidemiology, Management and Environmental Innovations
}

\author{
SA Kader ${ }^{1}$, SA Rob ${ }^{2}$
}

\begin{abstract}
Coronavirus disease 2019 (COVID-19) an infectious disease caused by severe acute respiratory syndrome coronavirus 2 (SARS-CoV-2) was first identified in 2019 in Wuhan, the capital of China's Hubei province, and has eventually spread to the size of pandemic. This article points outs the facts of its epidemiology and management in a thoughtful, brief, palatable, revealing and innovative way. This article also discusses a few innovations which could make the environment unfriendly to SARS-CoV-2.
\end{abstract}

Key words: COVID-19, SARS-CoV-2, Pandemic.

\section{Introduction}

Coronavirus disease 2019 (COVID-19), caused by severe acute respiratory syndrome coronavirus 2 (SARS-CoV-2) infection, was first identified in 2019 in Wuhan, the capital of China's Hubei province, spread globally, declared pandemic on March 11, 2020.1

Common symptoms include fever, cough, and shortness of breath. Muscle pain, sputum production, diarrhoea, sore throat, abdominal pain, and alsoloss of smell or taste occurs. 1 While the majority have mild symptoms, some progress to pneumonia and multi-organ failure. As of March 25, 2020, the overall rate of deaths per number of diagnosed cases is 4.5 percent; ranging from 0.2 percent to 15 percent according to age group and other health problems. The virus mainly spread during close contact and via respiratory droplets produced during coughing or sneezing. Respiratory droplets may be produced during breathing but the virus is not considered airborne. People may also catch COVID-19 by touching a contaminated surface and then their face. It is most contagious when people are symptomatic, although spread may be possible even before symptoms appear. 2 The virus can live on surfaces up to 72 hours.3 Time from exposure to onset of symptoms is generally between two and fourteen days, with an average of five days.4 The standard method of diagnosis is reverse transcription polymerase chain reaction (rRT-PCR) on a nasopharyngeal swab. The infection

1. Dr. Syed Abdul Kader, Assistant Professor, Depatment of Endocrinology, Sher-e-Bangla Medical College. 
can also be diagnosed from a combination of symptoms, risk factors and a chest CT scan showing features of pneumonia.5 Recommended measures to prevent infection include frequent hand washing, social distancing (maintaining physical distance from others, especially from those with symptoms), covering coughs and sneezes with a tissue or inner elbow, and keeping unwashed hands away from the face. 6 The use of masks is recommended by some national health authorities for those who suspect they have the virus and their caregivers, but not for the general public, although simple cloth masks may be used by those who desire them.There is no vaccine or specific antiviral treatment for COVID-19. Management involves treatment of symptoms, supportive care, isolation, and experimental measures.7 The World Health Organization (WHO) declared the 2019-20 coronavirus outbreak as a Public Health Emergency of International Concern (PHEIC) on 30th January 20208 and as a pandemic on March 11, 2020.1 Local transmission of the disease has been recorded in many countries across all six WHO regions. 9,10

\section{COVID-19 Epidemiology:}

- Corona virus (SARS-COV2) is the causative agent, its viability and virulence is important in transmission and disease severity.
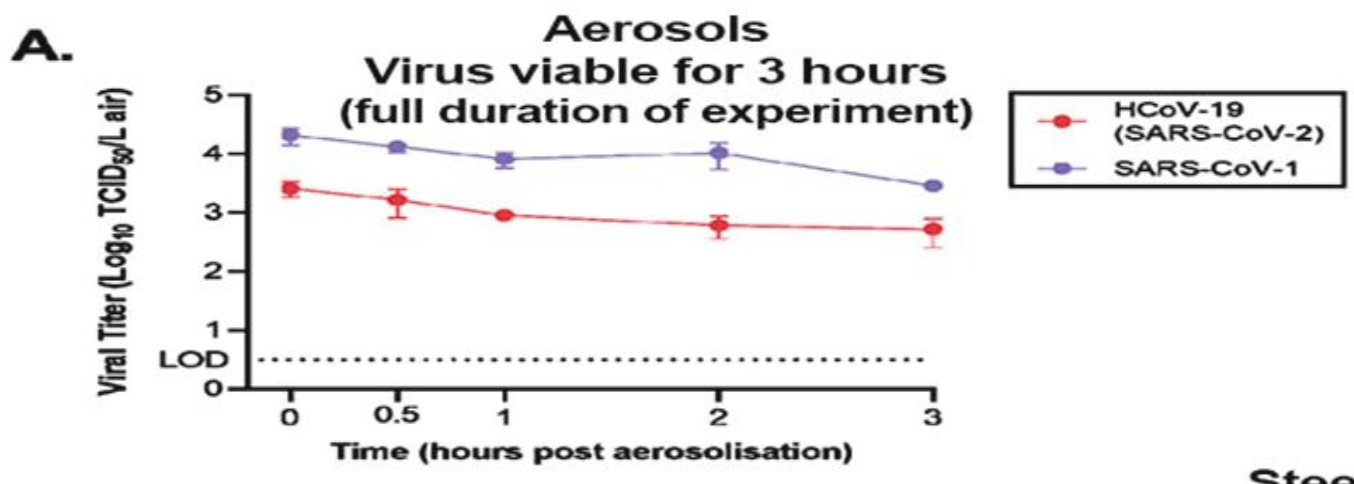

B.
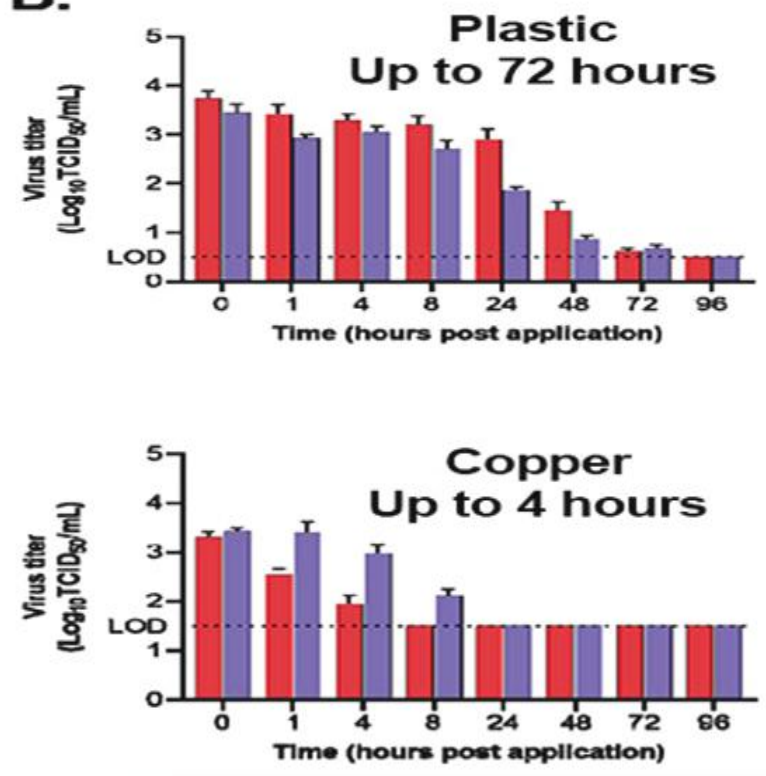
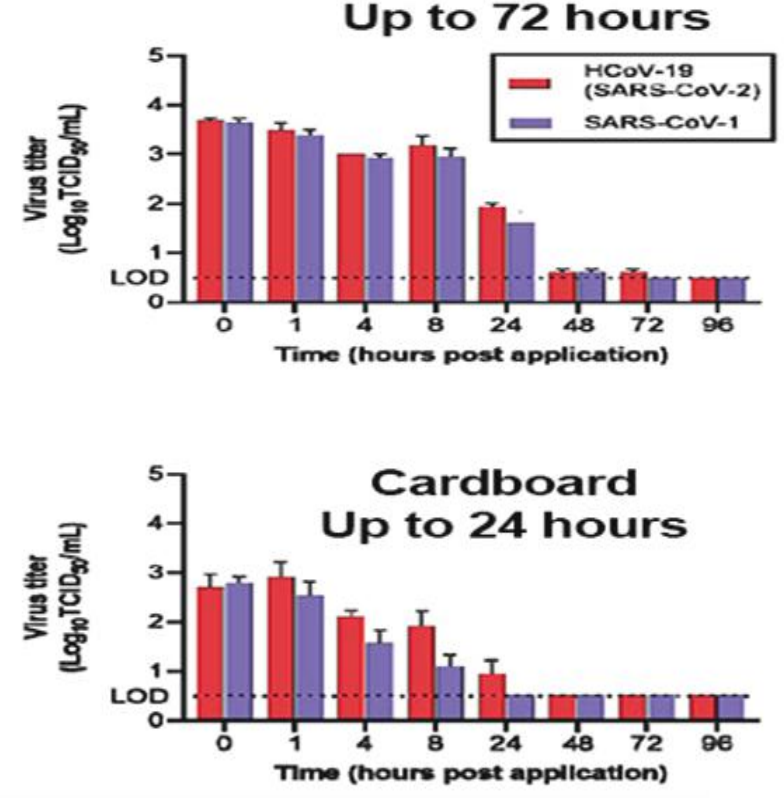


\section{Figure 01: Viability of SARS-COV2 on different surfaces 11}

- Connectivity (visitors to and from the country): The countries like USA, Italy, Spain which have greater number of people to tour in and out are more severely affected. Seven of the world's least visited places are free of COVID-19 till date (April 2020).10,12,13

- Climate: During the initial internatinal spread, the countries in temperate and tropical region which were in winter and spring seasons during the epidemic have been affected mainly. It looked like the virus replicated and transmitted better in the winter and spring of temperate region, winter of temperate region. The virus is viable for 3 hours in aerosol, up to 72 hours on plastic and steel, 4 hours on copper. 11

- Culture: Ways of social greetings, occurrence and frequency of social and religious congregation mattered. The societies with more frequent congregation, contact greetings, high cultural activities have been affected more, so far. Art loving catholic Italians have been affected severly. 14

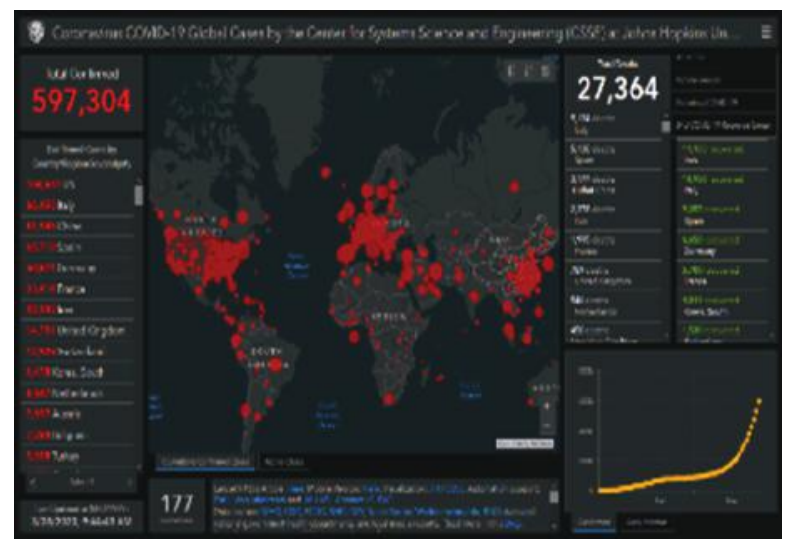

Figure 02: COVID-19 cases and deaths (source: CSSE, John Hopkins University)

- Care: Quality of health care and quicker application of new therapeutics kept down number of deaths. High standard of the Germans and rapid decision in applying novel therapeutics by the Chinese kept and brought down mortality to relatively lower levels. 11

- Co-morbidity: Control of co-morbidities like diabetes, asthma, ischaemic heart disease reduces the number of deaths. Co-morbidities increase infection rate, severity and mortality. 16

- Co-infection: Control of co-infection like influenza, bacterial pneumonia by preventive measures like vaccinationand therapeutic measures by antivirals, antibiotics reduces disease severity and the number of deaths. 17

- Concentration of population and crowding: High population density and overcrowding should facilitate the spread of COVID-19. So far, till the beginning of April, 2020, Bangladesh and India remained counterexamples probably due to lower connectivity than the western countries. 18

- Composition of population: Older persons have less functional reserve and weaker immunity. Italy has larger elderly population than the most of Europe and World who more likely to die of COVID19.14

- Control measures: Stricter and concerted control of transmissionreduces spread of infection, which actually occurred in South Korea at an early stage and in China at a later stage.19,20

- Code-genetics, immunogenic memory: Spanish flu regions-USA, UK, Spain, Italy have larger number of cases. USA, UK having more recent past Chinese connection within the last century, have fewer deaths/cases than Spain and Italy. The Chinese cases and deaths are plateauing to a standstill as of the start of April, 2020.20

- Cost bear ability: Richer countries has less under-testing and under-reporting showing greater incidence more reflecting actual epidemiology. 
- Comfort appliances: The climate congenial to the SARS-CoV-2 is also comfortable for human beings.COVID19 may transmit through air cooler, air conditioner, HVAC (heating, ventilating, air conditioning) system. This could be a cause of greater incidence in wealthier nations.

- Cold drinks and food: Soothing cold drinks and food may help the virus invade oropharynx.11

WORLD COVID-19 CASES AND DEATHS

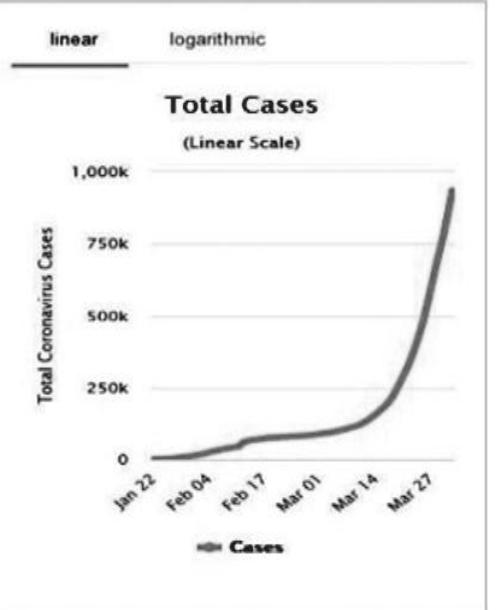

Total Coronavirus Cases in China

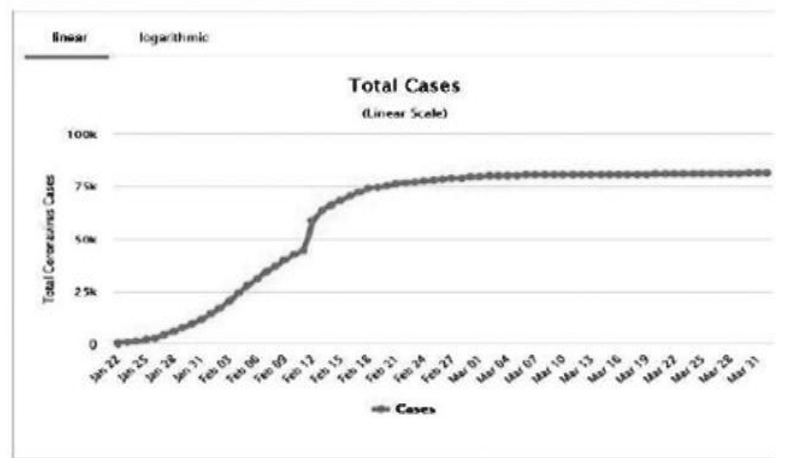

Figure 03: COVID-19 current status (before April 3, 2020) World vs China where it first appeared. China's concerted effort paying off: Immunogenesis, strict control, aggressive trials or all? Has the world got an evidence? (graphs source: CSSE, John Hopkins University)

\section{Management:}

- Maintaining Social distance: Public gossip, discussion, contact team sports, physically collective recreational, educational, social activities should be avoided.21,22

- Minimum Moving out of home: People

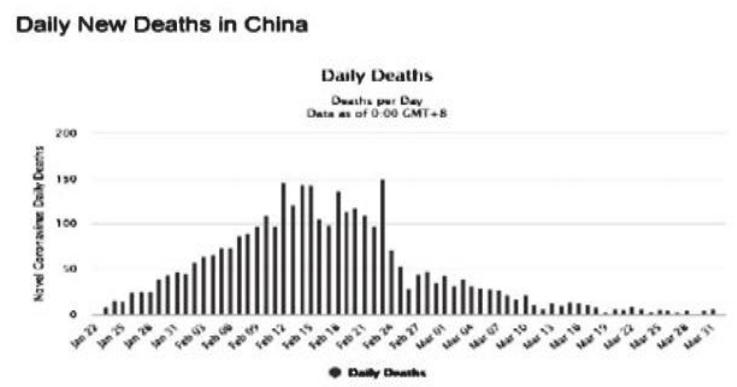

should go out only in need of living and sustenance, not for just wandering around.21,23

- Maintaining personal and hand hygiene :Secretions from nasopaharyngeal mucosa of one person should not be carried by air and hands to nasopaharyngeal mucosa of another person. Body secretions should not change biological surfaces before being washed out.21

- Early detection and isolation of cases: Clinical diagnosis confirmed by RT-PCR is the standard protocol.21

- In case of unavailability/unaffordability, serology may help $>5$ days post- 
symptom onset. Symptoms may vary from none to malaise, fever, cough, sore throat, shortness of breath sometimes requiring ventilation. Children and youth with minimum symptoms could be the missing link to rapid disease transmission. A patient should be suspected of the disease on both symptoms-signs and contact possibility.24

- Masks for at least suspected cases: Droplet distance and quantity reduction from the source is much easier and cheaper than protecting many potential healthy targets. 21,25

- Respirators, PPE: Must for the caregivers, sample handler (wearer's body should only touch the inside of the PPE, glove touches patient, don it last, doff it first, respirator protect wearer, doff it last). Respirators (N95, FFP2) should be worn on social occasions by the individuals of the vulnerable group, and in close gatherings or risky contacts by all.21,25

- Prevention: Environmental- air ionizer, electrostatic precipitators (scope for innovation like "Will balloons in nylon net fixed to the floor of a hall room act as droplet catchers? Will the virus get killed more quickly in a greenhouse with copper floor and furniture?"should be kept in mind. We must minimize droplet and dust generation). Human- active : vaccines, a few in clinical trial, many in preclinical research; passive : convalescent antiserum may work.24

- Treatment: Supportive- adequate nutrition and hydration, oxygen ventilation etc. Have separate apparatus like nebulizer and oxygen masks. Specific- antiviralFavipiravir, Danoprevir, Lopinavir/ Ritonavir have had success, non-antiviralchloroquine, hydroxychloroquine mainly inhibits cytokine storm. Co-infection, co-morbidity must be treated, people may die of these more than the disease. 21, 24
- Research : Like all the simple organisms, this virus is easily replicable in the laboratories with current technology, so vaccines and antivirals are likely to come soon, trials would take time. Assimple organisms mutate easily, so we have to adapt and grow our knowledge.

- Telemedicine from specialist physicians could be as good as PPE protected consultation.22, 25

- Prevent panic, take caution, isolate with respect, protect yourselves.

\section{Environmental innovations:}

\section{Air ioniser:}

An air ioniser(or negative ion generator or Chizhevsky's chandelier) is a device that uses high voltage to ionise (electrically charge) air molecules. Negative ions, or anions, are particles with one or more extra electrons, conferring a net negative charge to the particle. Cations are positive ions missing one or more electrons, resulting in a net positive charge. Some commercial air purifiers are designed to generate negative ions. Another type of air ioniser is the electrostatic discharge (ESD) ioniser (balanced ion generator) used to neutralise static charge.
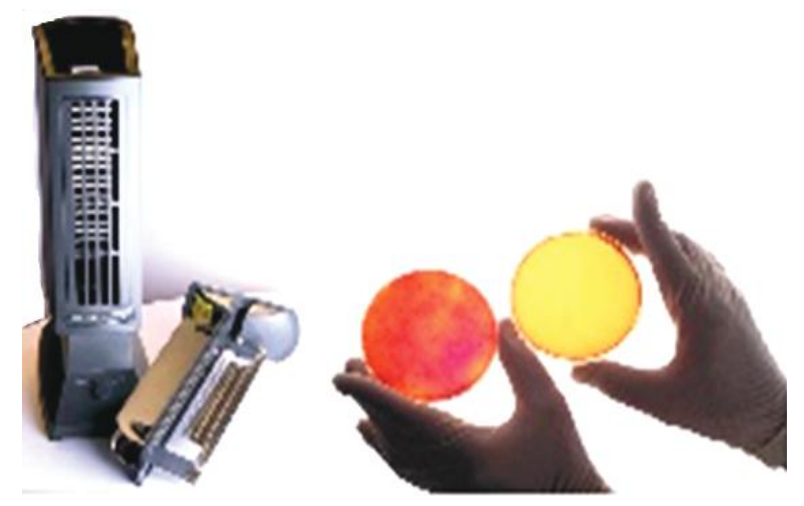

Figure 04: Air ionizer and collection plate and the effect on the culture media on the right with no growth (source: Laboratory US department of Agriculture) 
Air ionisershave been used to eliminate the occurrence of airborne bacterial infections and to reduce static electricity build-up in electronics. Air ionisersare used in air purifiers to remove particles from air. Airborne particles become charged as they attract charged ions from the ioniser by electrostatic attraction. The particles in turn are then attracted to any nearby earthed (grounded) conductors, either deliberate plates within an air cleaner, or simply the nearest walls and ceilings. The frequency of nosocomial infections in British hospitals prompted the National Health Service (NHS) to research the effectiveness of anions for air purification, finding that repeated airborne acinetobacterinfections in a ward were eliminated by the installation of a negative air ioniser-the infection rate fell to zero, which was an unexpected result. Positive and negative ions produced by air conditioning systems have also been found by a manufacturer to inactivate viruses including influenza.26

The SARS epidemic fuelled the desire for personal ionisers in East Asia, including Japan (where many products have been specialised to contain negative ion generators, including toothbrushes, refrigerators, air conditioners, air cleaners, and washing machines). There are two types of ionic air purifiers, the fanless and fan base ionizers. The fan base lonizers uses its fan to circulate air around the room rapidly but it is noisier and consumes more energy, while the fanless types distribute air slowly hence take a longer time to purify air but are noiseless and energy efficient.

\section{Electrostatic precepitator:}

An electrostatic precipitator (ESP) is a filtration device that removes fine particles, like dust and smoke, from a flowing gas using the force of an induced electrostatic charge minimally impeding the flow of gases through the unit.27 The most basic precipitator contains a row of thin vertical wires, and followed by a stack of large flat metal plates oriented vertically, with the plates typically spaced about $1 \mathrm{~cm}$ to $18 \mathrm{~cm}$ apart, depending on the application. The airstream flows horizontally through the spaces between the wires, and then passes through the stack of plates. A wet electrostatic precipitator (WESP or wet ESP) operates with water vapor

saturated air streams $(100 \%$ relative humidity). WESPs are commonly used to remove liquid droplets. The first portable electrostatic air filter systems for homes was marketed in 1954 by Raytheon.28. Ultra violet germicidal irradiation (UVIG) for fomites and High efficiency particulate air (HEPA) have been the other alternatives used previously for SARS, and these methods could be used in combination. 29

\section{Balloon- in-nylon-nets droplet catcher:}

This is a cheap, low technology alternative to commercial electrostatic precipitators. This can be made in any household without much effort and cost. Balloons should be snugly contained in nylon nets fixed at a low height to the floor of a bigger room of the household where bigger gathering may occur. Balloons low down will rub against the nylon, producing electrostatic charge, which will attract falling and passing droplets and droplet nuclei.

Presence of this assembly fixed to the floor will also create social distance as an added advantage. This assembly could be fixed to wheeled copper-plated flat vehicle, which could be sprayed with disinfectant and moved outside in the sun to kill the virus. 30 


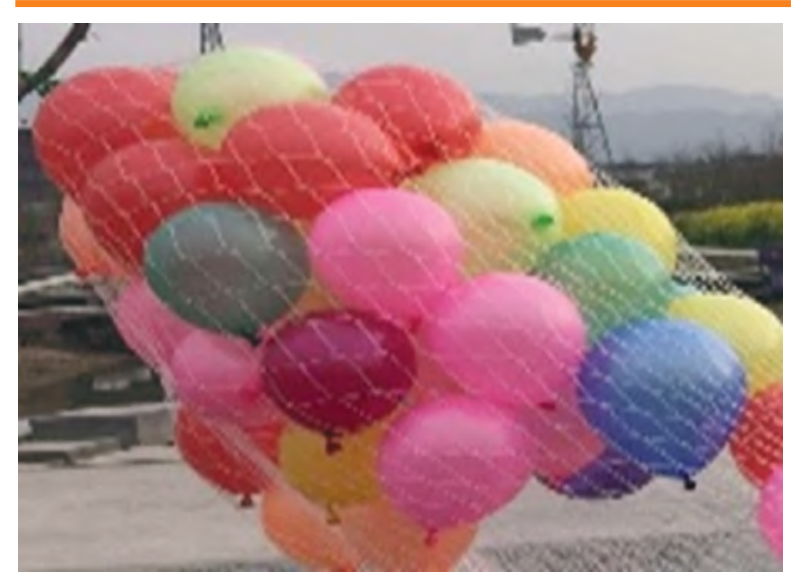

Figure 05: Balloon-in-nylon-nets droplet catcher 30

Greenhouse and copper plating:

SARS-CoV-2 should be quite similar to SARS CoV. The main route of transmission of SARS CoV infection is presumed to be respiratory droplets. The dried virus on smooth surfaces retained its viability for over 5 days at temperatures of $22-25^{\circ} \mathrm{C}$ and relative humidity of $40-50 \%$, that is, typical air-conditioned environments. However, virus viability was rapidly lost $(>3 \log 10)$ at higher temperatures and higher relative humidity (e.g., $38^{\circ} \mathrm{C}$, and relative humidity of $>95 \%$ ). 31 In a greenhouse, higher temperature would not be suitable for the virus to survive long. Moreover, direct UV light from the sun will accelerate its death. Copper plated furniture and copper covered floor will also make the surfaces less friendly for the virus. 30

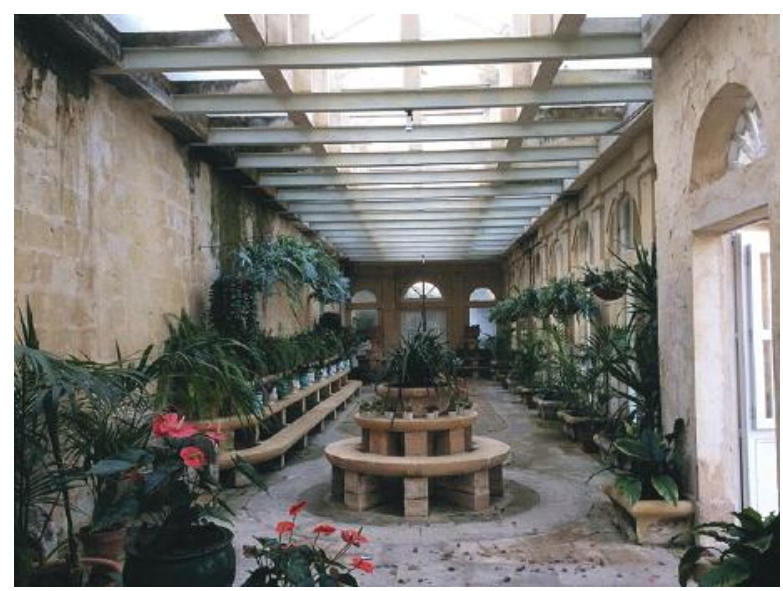

Figure 06: A greenhouse or half greenhouse 30

Imagine what would happen if all these conditions combine. Practically, it is feasible, and energy saving also, if someone lives in a house with transparent roof and many windows to minimize the risk of infections by SARS-CoV-2.

\section{Conclusion}

COVID-19 pandemic have raised worldwide concern \& anxiety. We should know the disease to fight it better. Modern science enables us to do so. At the same time, we should do the basics right. Besides high tech approach against the virus we should also look for a few innovations which have the least chance of tampering with the nature but as effective as ever. Doing the right thing rightly at the right time, is what is required most now. The scientists should propagate the core knowledge and instructional guideline from the discoveries they have made. This article tries to provide the core knowledge, and also encourage to innovate.

Conflict of interest: Authors declare that there is no conflict of interests.

\section{References}

01. "WHO Director-General's opening remarks at the media briefing on COVID-19-11 March 2020" (https://www.who.int/dg/speeches/det ail/who-director-general-s-opening-re $\mathrm{m}$ a r k s - a t - t h e m e d i a briefing-on-covid-19---11-march-2020) . World Health Organization. 11 March 2020. Retrieved 11 March 2020.

02. Coronavirus Disease 2019 (COVID-19) Symptoms. (https://www. cdc.gov/coronavirus/2019-ncov/about/ symptoms.html). Centers for Disease 
Control and Prevention. United States. 10February, 2020. Archived (https://web.archive.org/web/2020013 0202038/https://www.cdc.gov/coronav irus/2019-ncov/about/symptoms.html) from the original on 30 January 2020.

03. Coronavirus Disease 2019 (COVID-19) - Transmission. (https:// www.cdc.gov/coronavirus/2019-ncov/ prepare/transmission.html). Centers for Disease Control and Prevention. 17 March, 2020. Retrieved 23 March 2020.

04. New coronavirus-stable for hours on surfaces" (https://www.nih.gov/ news-events/news-releases/new-coro navirus-stable-hours-surfaces). National Institutes of Health. 17 March 2020.Retrieved 23 March 2020.

05. Velavan TP.; Meyer CG. (March 2020). The COVID-19 epidemic. Tropical Medicine \&International Health. n/a (n/a): 278-80. doi:10.1111/tmi.13383. (https://doi. org/10.1111\%2Ftmi.13383). PMID 32052514 (https://pubmed.cbi.nlm. nih.gov/32052514).

06. Jin $Y H$, Cai L, Cheng ZS, Cheng $H$, Deng T, Fan YP, et al. (February 2020). "A rapid adviceguideline for the diagnosis and treatment of 2019 novel coronavirus (2019-nCoV) infected pneumonia (standard version). (https://www.ncbi.nlm.nih.gov/pmc/arti cles/PMC7003341).Military Medical Research. 7(1): 4. doi:10.1186/s 40779-020-0233-6 (https:// doi.org/ 10.1186\%2Fs40779-020-0233-6). PMC $7003341 \quad$ (https:// www.ncbi.nlm.nih.gov/pmc/articles/P MC7003341). PMID 32029004 (https://pubmed.ncbi.nlm.nih.gov/3202 9004). coronavirus- 2019/ advice-for -public) from the original on 26 January 2020. Retrieved 25 February 2020.
08. Coronavirus Disease 2019 (COVID-19). (https:// www.cdc. gov/ coronavirus/2019-ncov/about/preventio n-treatment.html). Centers for Disease Control and Prevention (CDC). 15 February, 2020. Archived (https://web.archive.org/web/20200226 145347/https://www.cdc.gov/coronaviru s/2019-ncov/about/prevention-treatmen t.html) from the original on 26 February 2020. Retrieved 20 February 2020.

09. Statement on the second meeting of the International Health Regulations (2005) Emergency Committee regarding the outbreak of novel coronavirus (2019-nCoV). (https://www.who.int/news-room/detail /30-01-2020-statement-on-the-second -meeting-of-the-international-health-re gulations-(2005)-emergency-committe e-regarding-the-outbreak-of-novel-cor onavirus-(2019-ncov)). World Health Organization (WHO). Archived (https://web.archive.org/web/2020013 1005904/https://www.who.int/news-ro om/detail/30-01-2020-statement-on-th e-second-meeting-of-the-internationalhealth-regulations-(2005)-emergencycommittee-regarding-the-outbreak-ofnovelcoronavirus-(2019-ncov)) from the original on 31 January 2020. Retrieved 11 February 2020.

10. WHO Situation Report 65. (http://who.int/docs/default-source/cor onaviruse/situation-reports/20200325sitrep-65-covid-19.pdf) (PDF). WHO. 25 March 2020.

11. Doremalen NV, Bushmaker T, Morris $\mathrm{DH}$, Holbrook MG, Gamble A, Williamson BN. Aerosol and surface stability of HCoV-19 (SARS-CoV-2) compared to SARS-CoV-1. med Rxiv2020.03.09.20033217; doi: https://doi.org/10.1101/2020.03.09.20 033217 Now published in The New England Journal of Medicinedoi: 10.1056/NEJMc2004973 
12. Hamidi S, Sabouri S, Ewing R. Does Density Aggravate the COVID-19 Pandemic?, Journal of the American Planning Association. 2020; 86:4:495-509, DOI:10.1080/01944363.2020.1777891

13. Zheng $R, X u Y$, Wang $W$, Ning G, Bi $Y$. Spatial transmission of COVID-19 via public and private transportation in China. Travel Med Infect Dis. 2020 Mar-Apr;34:101626. doi: 10.1016/j.tmaid.2020.101626. Epub 2020 Mar 14. PMID: 32184132; PMCID: PMC7118651.

14. Cesari, M., Proietti, M. Geriatric Medicine in Italy in the Time of COVID-19. J Nutr Health Aging24, 459-460 (2020). https://doi.org/10.1007/s12603-020-13 54-z

15. Ridic G, Gleason S, Ridic O. Comparisons of health care systems in the United States, Germany and Canada. Mater Sociomed. 2012;24(2):112-20.

doi: $10.5455 / \mathrm{msm} .2012 .24 .112-120$. PMID: 23678317; PMCID: PMC3633404.

16. Singh AK, Gillies CL, Singh $R$, Singh A, Chudasama Y, Coles B, et al. Prevalence of co-morbidities and their association with mortality in patients with COVID-19: A systematic review and meta-analysis. Diabetes ObesMetab. 22:1915-1924; 2020. DOI: $10.1111 /$ dom.14124.

17. Langford BJ, So M, Raybardhan S, V Leung $V$, Westwood D, MacFadden DR, et al. Bacterial co-infection and secondary infection in patients with COVID-19: a living rapid review and meta-analysis. Clinical Microbiology and Infection 26 (2020) 1622-1629.

18. Brown LD. Comparing health systems in four countries: lessons for the United States. Am J Public Health. 2003 Jan;93(1):52-6. doi: 10.2105 lajph.93.1.52. PMID: 12511384; PMCID: PMC1447691.

19. Report of the WHO-China Joint Mission on Coronavirus Disease 2019 (COVID-19). 16-24 February 2020.

20. Wang, Xiaogiang and Tian, Weitian and LV, Xin and Shi, Yumiao and Zhou, Xiaoxin and $\mathrm{Yu}$, Weifeng and Su, Diansan and Tian, Jie, Effects of Chinese Strategies for Controlling the Growth Speed of the Cumulative Confirmed Cases of Novel Coronavirus-Infected Pneumonia in China (3/17/2020). Available at SSRN: https://ssrn.com/abstract=3557983 or http://dx.doi.org/10.2139/ssrn.3557983

21. National Guidelines on Clinical Management of Cornavirus Disease 2019 (Covid-19). Version 4.0. 30 March 2020.Disease Control Division,Directorate General of Health Services,Ministry of Health \& Family Welfare, Government of the People's Republic of Bangladesh.

22. Rockwell KL, Gilroy AS. Incorporating Telemedicine as Part of COVID-19 Outbreak Response Systems. The American Journal of Managed Care.Vol. 26, No. 4. 2020.

23. Anzai A, Kobayashi T, Linton NM , Kinoshita R, Hayashi K, Suzuki A, et al. Assessing the Impact of Reduced Travel onExportation Dynamics of Novel Coronavirus Infection (COVID-19). The Journal of Clinical Medicine. Published: 24 February 2020.

24. Pang J, Wang MX, Ang IYH, Tan SHX, Lewis RF, Chen Jl, et al. Potential Rapid Diagnostics, Vaccine and Therapeutics for 2019 Novel Coronavirus (2019-nCoV): A Systematic Review. J. Clin. Med. 2020, 9, 623; doi:10.3390/jcm9030623.

25. Infection prevention and control during health care when COVID-19 is suspected Interim guidance.19 March 2020. World Health Organization.

26. McDowell, Natasha (3 January 2003). Air ionisers wipe out hospital. 
infections. (https:// www.news cientist. com/article/dn3228-air-ionisers-wipe-o ut-hospital-infections/). The New Scientist(Daily news). Retrieved 24 August 2016.

27. Farnoud A (2008). Electrostatic Removal of Diesel Particulate Matter. ProQuest. p. 23. ISBN 978-0549508168.

28. Plug-in Filter Clears the Air. (https://books.google.pl/books?id=zS ADAAAAMBAJ\&pg=PA70). Popular Science. 165(1). Jul 1954. p. 70.

29. Rezaie A, Leite GGS, Melmed GY, Mathur R, Villanueva-Millan MJ, et al. (2020) Ultraviolet A light effectively reduces bacteria and viruses including coronavirus. PLOS ONE 15(7):
0236199. https:// doi.org/ 10.1371/ journal.pone.0236199.

30. Kader SA. Rewarded solution. Diminishing the Transmision of COVID-19. Innocentive Challege. ID-9934288.

31. Chan KH, Peiris JS, Lam SY, Poon LL, Yuen KY, Seto WH. The Effects of Temperature and Relative Humidity on the Viability of the SARS Coronavirus. Advances in Virology. Hindawi Publishing Corporation Volume 2011, Article ID 734690, 7 pages.

doi:10.1155/2011/734690 